\title{
Satellite Symposium "The Kidney and Hypertension" of The 36th Congress of the International Union of Physiological Sciences (IUPS), July 24-25, 2009 Tokyo, Japan
}

To understand the kidney function and control hypertension leading to chronic kidney disease (CKD)

\section{Guest Editors}

Kawahara K (Sagamihara), Kusano E (Shimotsuke), Mitarai T (Kawagoe), Tomita K (Kumamoto), and Uchida S (Tokyo)

\section{Special advisors}

Kimura G (Nagoya), Lang F (Tübingen), Palmer LG (New York) (a)

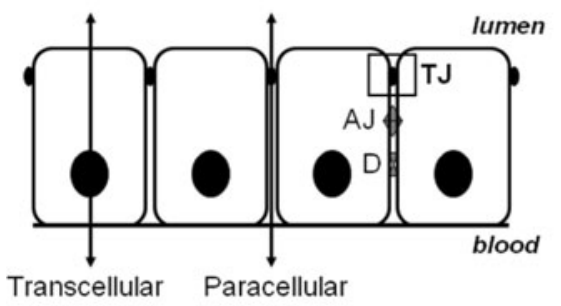

(c)

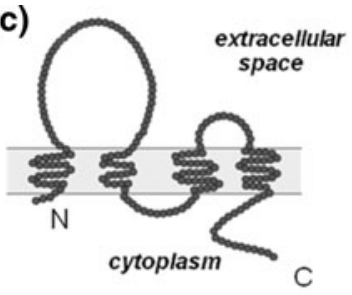

(b)

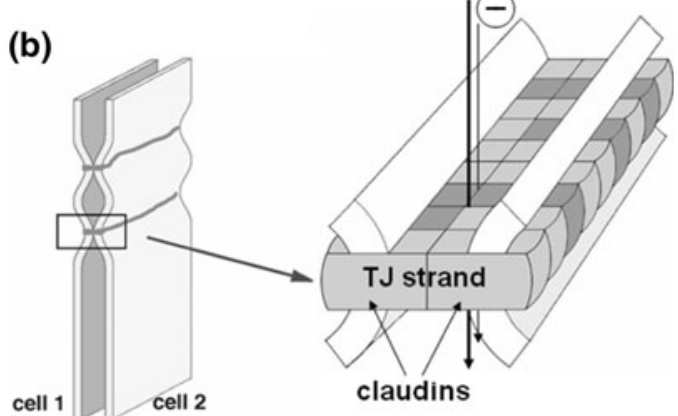

Schematic representation of claudin-based tight junctions in epithelia, from the paper by S. Muto et al. in this issue 